observation is therefore consistent with previous reports that have been unable to show that N95 masks were superior to 3ply masks in preventing transmission to HCWs performing AGPs. Further randomized control trial on ascertaining the effectiveness of the N95 respirators or medical masks in preventing HCWs from SARS-CoV-2 are warranted.

Acknowledgments. We thank the HCWs who consented to participate in the study.

Financial support. No financial support was provided relevant to this article.

Conflicts of interest. All authors report no conflicts of interest relevant to this article.

\section{References}

1. MacIntyre CR, Wang Q, Cauchemez S, et al. A cluster randomized clinical trial comparing fit-tested and non-fit-tested N95 respirators to medical masks to prevent respiratory virus infection in health care workers. Influenza Other Respir Virus 2011;5:170-179.

2. Smith JD, MacDougall CC, Johnstone J, Copes RA, Schwartz B, Garber GE. Effectiveness of N95 respirators versus surgical masks in protecting health care workers from acute respiratory infection: a systematic review and meta-analysis. CMAJ 2016;188:567-574.

3. Kangqi Ng, Beng Hoong Poon, et al. COVID-19 and the risk to health care workers: a case report. Ann Intern Med 2020;172:766-767.

4. Bartoszko JJ, Farooqi MAM, Alhazzani W, Loeb M. Medical masks vs N95 respirators for preventing COVID-19 in healthcare workers: a systematic review and meta-analysis of randomized trials. Influenza Other Respir Virus 2020;14:365-373.

5. Xiao J, Shiu EYC, Gao H, et al. Nonpharmaceutical measures for pandemic influenza in nonhealthcare settings-personal protective and environmental measures. Emerg Infect Dis 2020;26:967-975.

6. Jefferson T, Foxlee R, Del Mar C, et al. Physical interventions to interrupt or reduce the spread of respiratory viruses: systematic review. BMJ Clin Res 2008;336(7635):77-80.

7. Ong SWX, Tan YK, Chia PY, et al. Air, Surface environmental, and personal protective equipment contamination by severe acute respiratory syndrome coronavirus 2 (SARS-CoV-2) from a symptomatic patient. JAMA 2020;323:1610-1612.

8. Offeddu V, Yung CF, Low MSF, Tam CC. Effectiveness of masks and respirators against respiratory infections in healthcare workers: a systematic review and meta-analysis. Clin Infect Dis 2017;65:1934-1942.

9. Coia JE, Ritchie L, Adisesh A, et al. Guidance on the use of respiratory and facial protection equipment. J Hosp Infect 2013;85:170-182.

\title{
Sphingomonas paucimobilis infection among a patient with a history of injection drug use: An opportunity for improvement of medical chart documentation
}

\author{
Michael A. Goulart MPH, CIC, Marko Predic MS, CIC and Chad D. Neilsen MPH, CIC \\ Infection Prevention and Control, University of Florida Health Jacksonville, Jacksonville, Florida
}

To the Editor-At our level 1 academic trauma center in northeastern Florida, a patient developed a central-line-associated bloodstream infection (CLABSI) with Sphingomonas paucimobilis, an aerobic gram-negative bacillus that more commonly occurs in immunocompromised persons and is less commonly associated with nosocomial transmission. ${ }^{1-3}$ This patient was a female in her late twenties who was admitted for multifocal pneumonia after several days of cough and shortness of breath. Her medical history was remarkable for Hodgkin's lymphoma, chronic hepatitis $\mathrm{C}$ infection, thrombocytopenia, neutropenia, excoriation, tobacco use, and injection drug use (oxycodone). She denied current drug use. A double-lumen power peripherally inserted central catheter (PICC) was placed and dressed with a transparent dressing and chlorhexidine-gluconate impregnated antimicrobial disc (BioPatch) according to hospital policy. Approximately 1 month into her stay, blood cultures were positive for S. paucimobilis. Medical staff had documented patient noncompliance with hospital polices, such as dressing changes, on multiple occasions. After a 57-day stay, the patient was discharged to home hospice.

Author for correspondence: Michael Goulart, E-mail: michael.goulart@jax.ufl.edu Cite this article: Goulart MA, Predic M, and Neilsen CD. (2021). Sphingomonas paucimobilis infection among a patient with a history of injection drug use: An opportunity for improvement of medical chart documentation. Infection Control \& Hospital Epidemiology, 42: 1152-1153, https://doi.org/10.1017/ice.2020.430
Whether the patient acquired S. paucimobilis due to her immunocompromised state and/or noncompliance with hospital policies is unknown. There was a paucity of information regarding her past history of injection drug use, as documented by clinical staff during her admission. Current injection drug use may have contributed to the development of the CLABSI. Walayat et $\mathrm{al}^{4}$ noted the isolation of $S$. paucimobilis in an injection drug user, which presented itself as acute phlebitis; these authors suspected the patient acquired the organism from using toilet water to mix heroin prior to injecting. ${ }^{4}$ We urge clinicians to thoroughly document past drug use, especially among past and current injection drug users, to note when suspected drug use has occurred, and/or to note suspicion if a patient has accessed their own vascular catheter. This is critical in wake of the ongoing opioid epidemic linked to injection drug use, which has affected many states across the United States, including Florida, which has also been facing an ongoing outbreak of the hepatitis A virus. Since January 2018, more than one-third of reported cases in the state have reported injection drug use. ${ }^{5}$ According to the Centers for Disease Control and Prevention (CDC) National Healthcare Safety Network definitions, even if a patient accesses their own vascular catheter during their hospital stay, whether through injection drug use or other means, and it meets the CLABSI case definition, it is still attributed to the reporting facility. ${ }^{6}$ The CDC recommend that risk mitigation include a sitter for the patient and/or removing the tunneled catheter as soon as clinically 
possible. Providing a sitter may not always be feasible, especially in light of ongoing novel coronavirus pandemic. ${ }^{6}$

Acknowledgments. None.

Financial support. No financial support was provided relevant to this article.

Conflicts of interest. All authors report no conflicts of interest relevant to this article.

\section{References}

1. Dworkin M, Falkow S, Rosenberg E, Schleifer K, Stackebrandt E. The Prokaryotes. Vol 7. New York, NY: Springer-Verlag; 2007:206-226.
2. Kilic A, Senses Z, Kurekci A, Aydogan H, Basustaoglu A. P592 Nosocomial outbreak of Sphingomonas paucimobilis bacteraemia in an oncology and haematology unit. Int J Antimicrob Agents 2007;29:S137.

3. Toh HS, Tay HT, Kuar WK, Weng TC, Tang HJ, Tan CK. Risk factors associated with Sphingomonas paucimobilis infection. J Microbiol Immunol Infect 2011;44:289-295.

4. Walayat S, Malik A, Hussain N, Lynch T. Sphingomonas paucimobilis presenting as acute phlebitis: a case report. IDCases 2017;11:6-8.

5. Hepatitis A surveillance, July 2020. Florida Department of Health website. http://www.floridahealth.gov/diseases-and-conditions/vaccine-preventabledisease/hepatitis-a/surveillance-data/_documents/2020-july-hep-a-report.pdf. Published August 11, 2020. Accessed August 17, 2020.

6. NHSN frequently asked questions: central line-associated bloodstream infection. Centers for Disease Control and Prevention website. https://www.cdc. gov/nhsn/PDFs/faqs/FAQs-V-6_CLABSI.pdf. Accessed January 14, 2020.

\title{
Antimicrobial stewardship programs and convalescent plasma for COVID-19: A new paradigm for preauthorization?
}

\author{
Michael P. Stevens MD, MPH${ }^{1}$, Payal K. Patel MD, MPH ${ }^{2,3}$ (1) and Priya Nori MD ${ }^{4}$ \\ ${ }^{1}$ Healthcare Infection Prevention Department, Virginia Commonwealth University Health System, Richmond, Virginia, ${ }^{2}$ Infectious Diseases Section, Ann Arbor \\ VA Medical Center, Ann Arbor, Michigan, ${ }^{3}$ University of Michigan, Ann Arbor, Michigan and ${ }^{4}$ Division of Infectious Diseases, Department of Medicine, \\ Montefiore Medical Center, Albert Einstein College of Medicine, Bronx, New York
}

To the Editor-Antimicrobial preauthorization is a core strategy utilized by antimicrobial stewardship programs (ASPs). ${ }^{1}$ ASPs have played an important role in coronavirus disease 2019 (COVID-19) response efforts, including in the preauthorization of novel therapeutic agents such as remdesivir., ${ }^{2,3}$ On August 23, 2020, the US Food \& Drug Administration (FDA) released an emergency use authorization (EUA) for the use of convalescent plasma in treating hospitalized patients with COVID-19. ${ }^{4}$ An important question is what role, if any, ASPs should play in the convalescent plasma distribution process. To our knowledge, ASPs have never been involved in the preauthorization of blood products like convalescent plasma. There are numerous potential advantages and disadvantages to consider regarding ASP involvement in the convalescent plasma preauthorization process (Table 1). The effectiveness of convalescent plasma in the treatment of COVID-19 is still unclear. The data regarding convalescent plasma use are limited. As of June 22, 2020, the Infectious Diseases Society of America (IDSA) COVID-19 treatment guidelines recommend the use of convalescent plasma only in the context of a clinical trial. ${ }^{5}$ Importantly, enrollment in existing trials has been potentially compromised by the EUA announcement. Major scientific organizations will likely continue to support guidelines emphasizing convalescent plasma use only in the context of clinical trials. It is also possible that additional study data will become

\footnotetext{
Author for correspondence: Michael P. Stevens, E-mail: michael.stevens@vcuhealth. org

Cite this article: Stevens MP, Patel PK, and Nori P. (2021). Antimicrobial stewardship programs and convalescent plasma for COVID-19: A new paradigm for preauthorization?. Infection Control \& Hospital Epidemiology, 42: 1153-1154, https://doi.org/10.1017/ ice. 2020.459
}

available that will influence convalescent plasma use. This uncertainty about the optimal role of convalescent plasma supports the use of preauthorization to allow for real-time adjustment of convalescent plasma use in a controlled, optimized fashion.

Many ASPs have been responsible for the creation and maintenance of COVID-19 treatment guidelines and are ideally situated to inform frontline clinicians about the optimal use of convalescent plasma relative to other therapies. Preauthorization, coupled with local treatment guidelines, would enhance the optimal use of convalescent plasma. Additionally, the new convalescent plasma EUA may increase demand for convalescent plasma use, resulting in timely access issues. A preauthorization process utilizing the best available evidence would facilitate providing convalescent plasma to patients who may benefit.

Health systems would benefit tremendously from ASP involvement in the COVID-19 convalescent plasma distribution process. ASPs can provide guidance for incorporation of convalescent plasma into local treatment guidelines, can provide insight and guidance based on their experiences with other COVID-19 focused EUAs (including hydroxychloroquine, now revoked ${ }^{6}$, and remdesivir $^{7}$ ), and can help develop processes for convalescent plasma eligibility screening and preauthorization. If health systems do not adopt preauthorization for convalescent plasma, we recommend that use be carefully monitored to ensure that this resource is being used optimally. ASPs have proven integral in COVID-19 response efforts-investing in and scaling up ASP resources will assist health systems adapt and respond to evolving pandemic challenges.

Financial support. No financial support was provided relevant to this article. Conflicts of interest. All authors report no conflicts of interest relevant to this article.

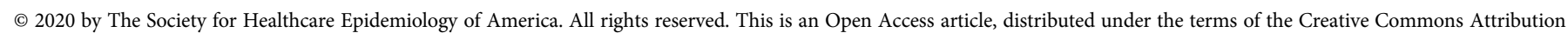

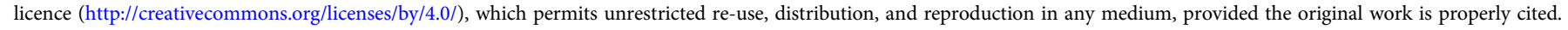

